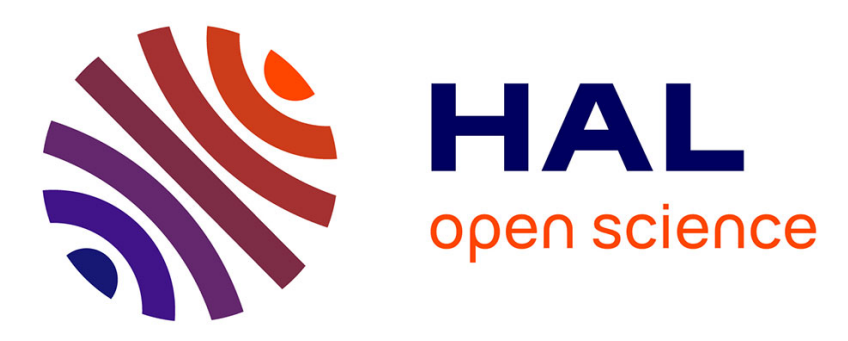

\title{
Diffuse Coplanar Surface Barrier Discharge and its applications for in-line processing of low-added-value materials
}

\author{
M. Černák, L'. Černáková, I. Hudec, D. Kováčik, A. Zahoranová
}

\section{To cite this version:}

M. Černák, L'. Černáková, I. Hudec, D. Kováčik, A. Zahoranová. Diffuse Coplanar Surface Barrier Discharge and its applications for in-line processing of low-added-value materials. European Physical Journal: Applied Physics, 2009, 47 (2), pp.1-6. 10.1051/epjap/2009131 . hal-00497324

\author{
HAL Id: hal-00497324 \\ https://hal.science/hal-00497324
}

Submitted on 4 Jul 2010

HAL is a multi-disciplinary open access archive for the deposit and dissemination of scientific research documents, whether they are published or not. The documents may come from teaching and research institutions in France or abroad, or from public or private research centers.
L'archive ouverte pluridisciplinaire HAL, est destinée au dépôt et à la diffusion de documents scientifiques de niveau recherche, publiés ou non, émanant des établissements d'enseignement et de recherche français ou étrangers, des laboratoires publics ou privés. 


\title{
DIFFUSE COPLANAR SURFACE BARRIER DISCHARGE AND ITS APPLICATIONS FOR IN-LINE PROCESSING OF LOW-ADDED- VALUE MATERIALS
}

\author{
Černák M. ${ }^{\mathrm{a}, \mathrm{b}}$, Černáková L. ${ }^{\mathrm{c}}$, Hudec I. ${ }^{\mathrm{c}}$, Kováčik D. ${ }^{\mathrm{a}}$, and Zahoranová A. ${ }^{\mathrm{a}}$ \\ a) Faculty of Mathematics, Physics and Informatics (Department of Experimental Physics, Comenius University, \\ Mlynská dolina, 84248 Bratislava, Slovak Republic) \\ b) Faculty of Science (Department of Physical Electronics, Masaryk University, Kotlárská 2, 61137 Brno, \\ Czech Republic) \\ c) Slovak University of Technology (Institute of Polymer Materials, Radlinského 9, 81237 Bratislava, \\ Slovak Republic)
}

\begin{abstract}
The paper reviews a current state of the art in the in-line plasma treatment of low-cost materials and opportunities for the use of the so-called Diffuse Coplanar Surface Dielectric Barrier Discharge (DCSBD). A brief outline of physical mechanism and basic properties of DCSBD is given. The results presented on the ambient air plasma treatments of textile, paper, wood, and glass illustrate that DCSBD offers outstanding performance with extremely low energy consumption for large area, uniform surface modifications of materials under continuous process conditions.
\end{abstract}

\section{INTRODUCTION}

In recent years, low temperature atmospheric pressure plasma surface treatments (APPSTs) have become a hot topic because of the potential of fast and efficient in-line processing fabrication without expensive vacuum equipment $[1,2]$. The potential economic and operation advantages of coating at $1 \mathrm{~atm}$ have led to the development of a variety of APPST reactors [1-4]. It is apparent, however, that only a very limited number of the APPST reactors discussed in the technical literature have proven practicable or economic for the intended in-line industrial applications.

A serious obstacle to commercializing the in-line APPST on a large industrial scale is the necessity to reduce the treating times to values less than $1 \mathrm{sec}$, which requires a plasma power density at least of the order of $10 \mathrm{~W} / \mathrm{cm}^{3}$. This is an uneasy task because increasing the deposited power density the plasma has the tendency of filamentation and to transition into a spark or arc discharge. As a consequence, a common theme of many atmospheric pressure plasma approaches is that a helium and occasionally neon containing working gas is required to operate the discharge in glow-like regime and to prevent the plasma filamentation and sparking $[5,6,7]$. However, the costs associated with using large amounts of noble gases makes such APPSTs impractical to use in industries requiring high rates of throughput of low-cost materials, e.g., the textile and paper industries. In contrast to the glowdischarge-like discharge in the noble gases a diffuse low-current "Townsend-like" discharge is generated in atmospheric-pressure nitrogen [8, 9]. Plasma power density of such discharge is, however, much less than the required $10 \mathrm{~W} / \mathrm{cm}^{3}$, and oxygen admixtures of some hundreds parts-permillion lead to the generation of the filamentary micro-discharges [9].

In an in-line processing at atmospheric pressure, it is very difficult to operate in a completely air-free plasma gas. This problem is particularly difficult when porous materials such as fabrics and paper are treated at high line speeds. Because of this and also because of the gas economy issue, in practice it turned out that "ambient air" is considered to be the ideal discharge atmosphere for most APPST applications. As a consequence, discussing the in-line surface plasma treatments of relatively low-cost materials we shall restrict ourselves to the plasma sources capable to generate highly non-equilibrium ambient air plasmas with the power density higher than the order of $1 \mathrm{~W} / \mathrm{cm}^{3}$.

\footnotetext{
a Electronic address: cernak@fmph.uniba.sk
} 


\section{PLASMA SOURCES FOR AMBIENT AIR APPST}

Non-thermal, ambient temperature and pressure natural air plasmas avoid the restrictions imposed by costly, cumbersome vacuum chambers and by expensive plasma gases, but, at the same time, they vastly complicate the plasma physics involved. A major problem of APPSTs in air is insufficient treatment uniformity because, particularly at the plasma power densities above of some $10 \mathrm{~W} / \mathrm{cm}^{3}$, the air plasma has the tendency of filamentation and to transition into an arc discharge.

Until today, the only actual commercial plasma devices widely-used for continuous high-speed processing of large-area materials in air are based on filamentary volume dielectric barrier discharges often marketed as „corona“ or ,industrial corona“ treaters $[1,10]$. Their commercial applications, however, are restricted to improving the surface energy of thin plastic films and foils since for the thicker materials the overall resistance between the electrodes is too high to ignite the discharge. Also, the "corona" treatment is not practical and efficient enough for the high-speed treatment of porous materials like fabrics and paper [1,2,11].

A typical "industrial corona" or more correctly a volume Dielectric Barrier Discharge (DBD), device consists of two metal electrodes, in which at least one, usually a grounded metal roll, is coated with a dielectric layer. The gap between the electrodes, where the plasma is generated, is in the order of several $\mathrm{mm}$, and the applied voltage is about $20 \mathrm{kV}$. The atmospheric-pressure plasma is generated through a succession of micro streamers, lasting for 10-100 ns, and randomly distributed in space and time. The streamers are some $100 \mu \mathrm{m}$ in diameter and are separated from each other. The acceptable plastic film or foil treatment uniformity is due to the tendency of streamers to spread and expand along the treated solid dielectric film surface. While this treatment is generally effective, it makes the film surface rough. Moreover, because of the treatment nonuniformity the effect of volume DBD discharge treatment on the film surface may degrade with time. Accordingly, the treatment is generally only useful if it can be done in line with the coating of the film.

In recent years it was found $[10,12]$ that under special conditions, it is possible to generate "truly random" volume DBD exhibiting a pseudo-glow character. It was found that the apparent inhomogenity of such filamentary discharge does not necessarily lead to an operational disadvantage, i.e. the resultant treatments are effectively surface uniform. Nevertheless, the filament randomization does not prevent that the volume DBDs in air produce a relatively low average density of active species because most of the atoms and radicals are produced inside the narrow microdischarge filaments and are rapidly lost to recombination.

Consequently, there is a strong desire to avoid the plasma filamentation $[4,16,17]$, and the term „atmospheric pressure glow plasma“ is often used for a surface modification technique that is similar to the filamentary volume DBD treatment, but with more control, greater uniformity, and higher efficiency. For example, it is known that, the polypropylene wettability increase by a diffuse glow volume DBD is greater and more stable than by a filamentary DBD $[13,14]$.

The developments of novel types of electrode systems and a fuller understanding of the underlying discharge physics has it now made possible to construct atmospheric-pressure plasma ambient air reactors operating in a glow discharge mode, i.e., based on the so-called atmospheric-pressure glow discharges (APGD) with a homogeneous volumetric plasma structure similar to that of low pressure plasmas [1, 15-17]. A very important requirement to obtain a satisfactory, uniform APGD remains the air flow. Without sufficient air flow, an air discharge may break up into an array of thin streamer filaments [1, 15-17]. In practice, however, it is difficult and tricky to reliably control such homogeneous glow discharges at atmospheric pressure. For example, minor changes in the electrode configuration, small variations of the amplitude or repetition frequency of the applied voltage, or increased air humidity can cause a transition from the relatively unstable glow mode to that of a much more stable filamentary discharge. For many potential industrial applications, this latter behavior is a severe disadvantage and, consequently, the commercial use of the available ambient air APGD systems for industrial processing is still almost none.

The air flow is an important plasma stabilizing factor also in the plasma jets, where the surfaces are treated in the non-equilibrium plasma jet emerging from the plasma generating discharge. This is 
because that the temperature directly inside the discharge is too high for direct treatment in this zone. Surfaces are therefore treated in the downstream region, where the plasma jet or cloud emerges from the discharge. The air plasma jets are used routinely in surface treatment of three-dimensional workpieces as, for example, plastic bottles and car dampers. The reader is referred to a technical review [17] of the ambient air plasma jets based on arc and glidarc discharges. Ambient air plasma jets can be fed also, for example, by microwave discharges [19] and APGDs [16]. However, such plasma sources generate flowing relatively cold uniform air plasmas with the energy density up to some $10 \mathrm{~W} / \mathrm{cm}^{3}$ only. Besides the low plasma energy density, the principal shortcoming of these plasma sources relying on metastable and other long-lived neutral species is that they do not use the full potential of the discharge, including electrons, ions, as well as potentially the UV radiation emitted by the plasma to aid material processing. Also, usually they are producing the active long-lived species in amounts much larger than is the amount of active species actually reacting with the treated surface. As a consequence, a substantial part of the active species and discharge power is uselessly dissipated in the plasma volume and surrounding air by recombination processes and gas heating. This increases the power consumption up to such high levels as to make them incompatible with the low added value of the products like plastic films, metal foils, textile, paper and wood. Moreover, with conventional plasma jets only virtually circular contact areas of the emerging plasma jet on the surface to be processed can be achieved because of the common concentric electrode geometry. Thus, even when the ambient air plasma sources are claimed to be well implantable even in textile production lines [4], for uses over large areas the process requires an enormous amount of time and produces inhomogeneous surface structures.

From the above critical review it is evident that a need exists for a technically and economically feasible plasma source capable to generate ambient air plasma at the plasma power densities high enough to provide the high throughput needed for continuous processing of large-area low-addedvalue materials $[20,21]$.

\section{DIFFUSE COPLANAR SURFACE BARRIER DISCHARGES (DCSBD) IN AIR: BASIC PROPERTIES AND MECHANISM}

DCSBD plasma source has been developed to address the above discussed needs of industry. The idea is to generate a thin (on the order of $0.1 \mathrm{~mm}$ ) layer of plasma with a high power density in the immediate vicinity of the treated surface and bring it into a close contact with the treated surface. Such a diffuse plasma layer enables to use the full potential of the discharge, including charged species, atomic and radical species, as well as the UV radiation emitted by the air plasma to aid material processing. Consequently, it is believed to provide substantial advantages in energy consumption and exposure time.

A schematic diagram of a DCSBD electrode system designed for ambient air plasma generation is shown in Fig. 1. Two systems of parallel striplike electrodes $(1.8 \mathrm{~mm}$ wide, $\sim 0.1 \mathrm{~mm}$ thick, $230 \mathrm{~mm}$ long, $0.4 \mathrm{~mm}$ strip to strip; silver) were embedded in $96 \%$ alumina using a green tape technique. The thickness of the ceramic layer between the plasma and electrodes was $0.4 \mathrm{~mm}$. A sinusoidal high frequency high-voltage $\sim 10-20 \mathrm{kHz}$, up to $15 \mathrm{kV}$ peak to peak was applied between the electrodes.

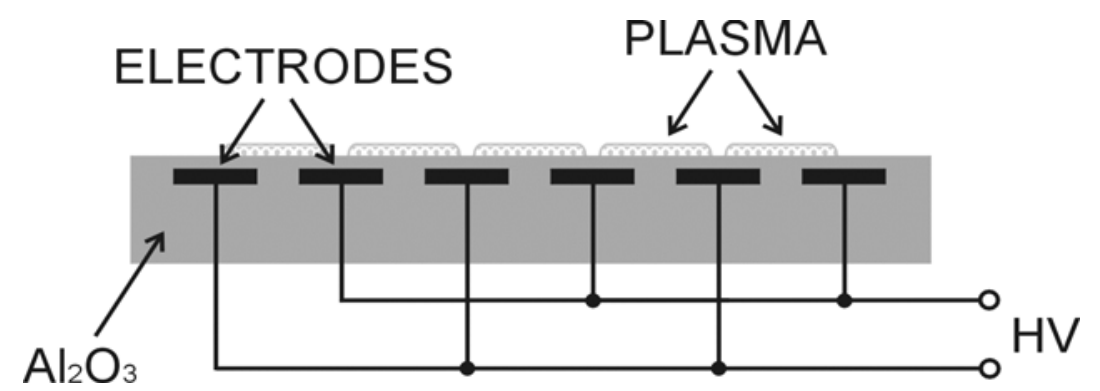

FIGURE 1. Cross-sectional schematics of DCSBD electrode system arrangement. 
Such a discharge electrode arrangement and energization were found to generate visually almost uniform plasmas in ambient air at atmospheric pressure that is illustrated by the time integrated CCD camera images of the discharge in Fig. $2 b$.

(a)

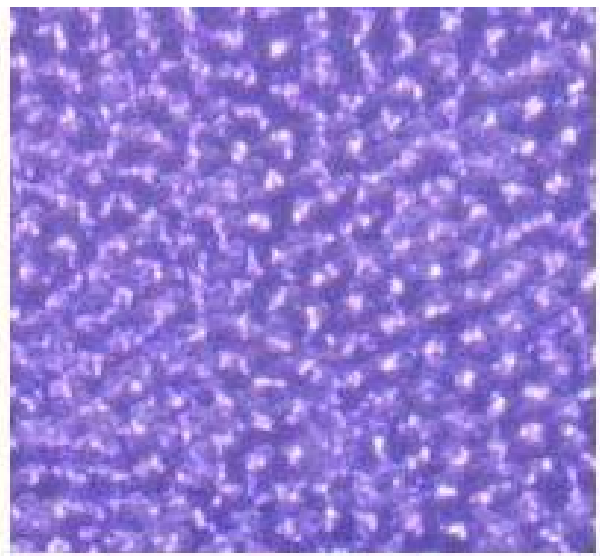

(b)

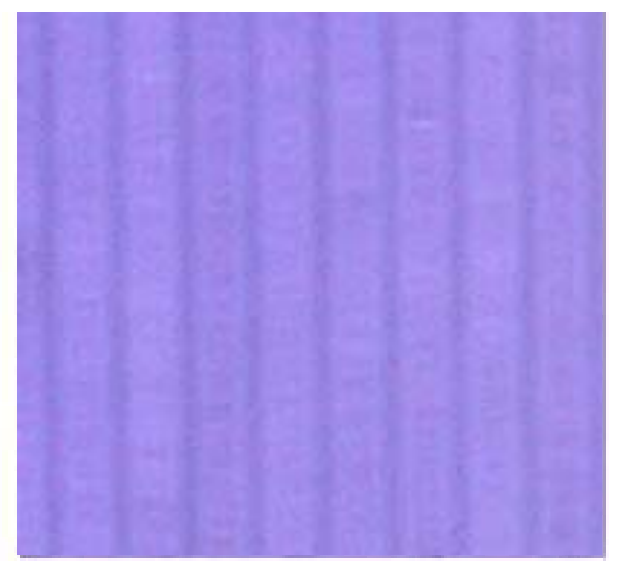

FIGURE 2. Visual appearance of one square centimeter area of a volume DBD and DCSBD. White spots in (a) are light from the microdischarges seen through a transparent electrode using a $2 \mathrm{~mm}$ inter-electrode gap. Both discharges were operated in ambient air at the same discharge power of $3 \mathrm{~W} / \mathrm{cm}^{2}$.

The visually diffuse plasma that is almost uniformly coating the alumina surface consists, in fact, from a diffuse surface discharge plasma generated on the electrode system surface over metal electrodes and a filamentary streamer plasma on the surface over the gap between electrodes. This is because the discharge consists of numerous $\mathrm{H}$-shaped elementary discharges developing with a high density and running on the electrode system surface along the embedded strip electrodes. At the discharge onset voltage, it is possible to stabilize several such elementary discharges distributed randomly over the electrode system surface. CCD camera pictures of such elementary discharges taken at the discharge onset voltage in air and nitrogen are shown in Fig. 3.

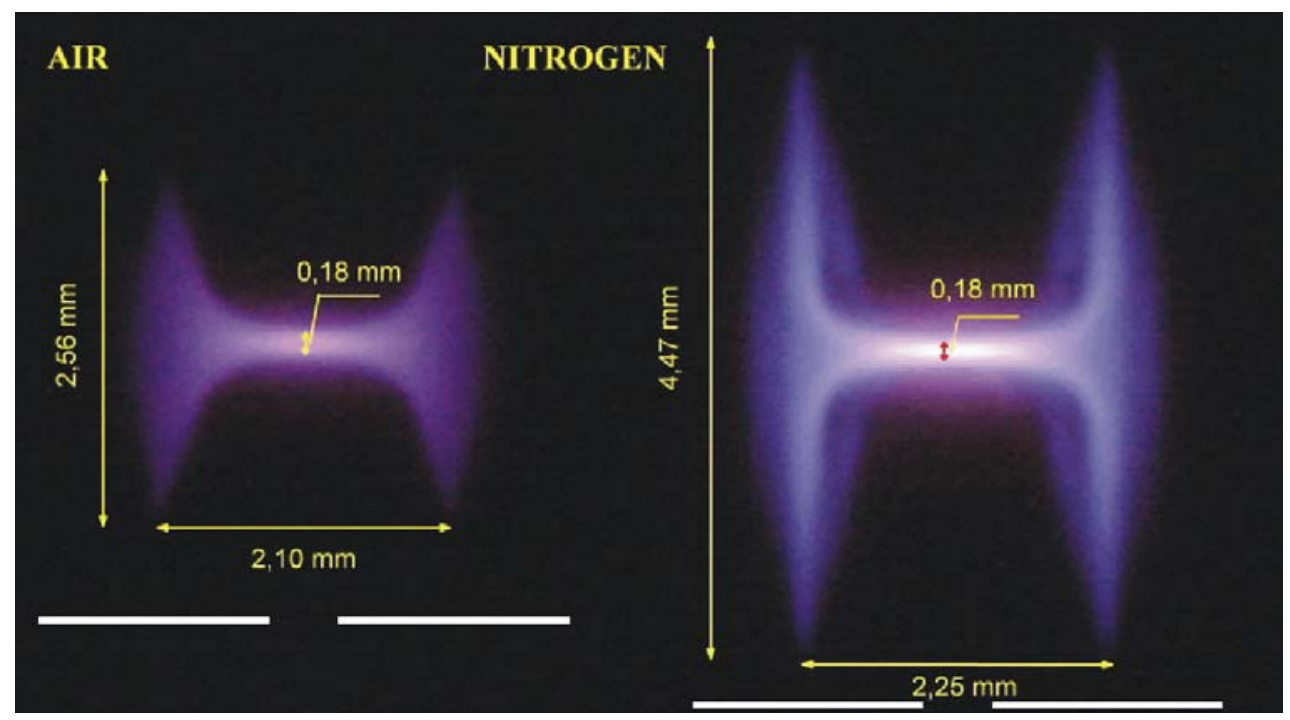

FIGURE 3. Images of elementary H-shaped discharges taken in air and nitrogen at the discharge onset peak-topeak voltages of 6.2 and $6.8 \mathrm{kV}$ respectively. Electrodes location is indicated by white lines.

The density and the movement velocity of the H-shaped elementary discharges increase with the gap voltage and the discharge power. Also with increasing gap voltage the diffuse plasma light emission (the vertical diffuse plasma areas in Fig. 3) strengthens compared to the streamer plasma emission (the horizontal bright plasma filament). As a result, the DCSBD discharge homogeneity tends to increase with increasing gap voltage. Such unique discharge behavior offers significant advantages 
over volume DBDs, APGDs, and plasma jets, where increasing the discharge power the plasma has the tendency of filamentation and to transition into a spark discharge.

An effective thickness of the plasma layer measured using a CCD camera [20] can be estimated to be about $0.3 \mathrm{~mm}$ that, at conditions the same as in Fig. $2 \mathrm{~b}$, gives the plasma power density of some $100 \mathrm{~W} / \mathrm{cm}^{3}$. It is apparent that the gas temperature of such thin air plasma layer depends strongly on the electrode system surface temperature that is effected also by the alumina ceramic dielectric heating. Nevertheless, using a simple cooling oil system, at continuous operation of the discharge at $100 \mathrm{~W} / \mathrm{cm}^{3}$ the rotational gas temperature can be kept as low as $377 \pm 18 \mathrm{~K}$ at the vibrational temperature of $2645 \pm 195 \mathrm{~K}$, as estimated from the band of $\mathrm{OH}$ and from the second positive nitrogen band system of nitrogen. A simple and persuasive illustration that the DCSBD air plasma is strongly non-isothermal and safe is the fact that it can be touched by hand (see, please, Ref. 33).

Despite the above mentioned unique characteristics of DCSBD, there is still a considerable room for improvement of its characteristics, which will require better understand the discharge physics. It is apparent that the DCSBD mechanism is very complex and there are many physical factors, such as the electrode geometry, permittivity and secondary electron emission of the dielectric material used, power supply characteristics, etc. that determine the DCSBD air plasma parameters. In our opinion, a necessary first step is the understanding of the formation and characteristics of the diffuse surface DBD plasma over a wide range of conditions and parameters.

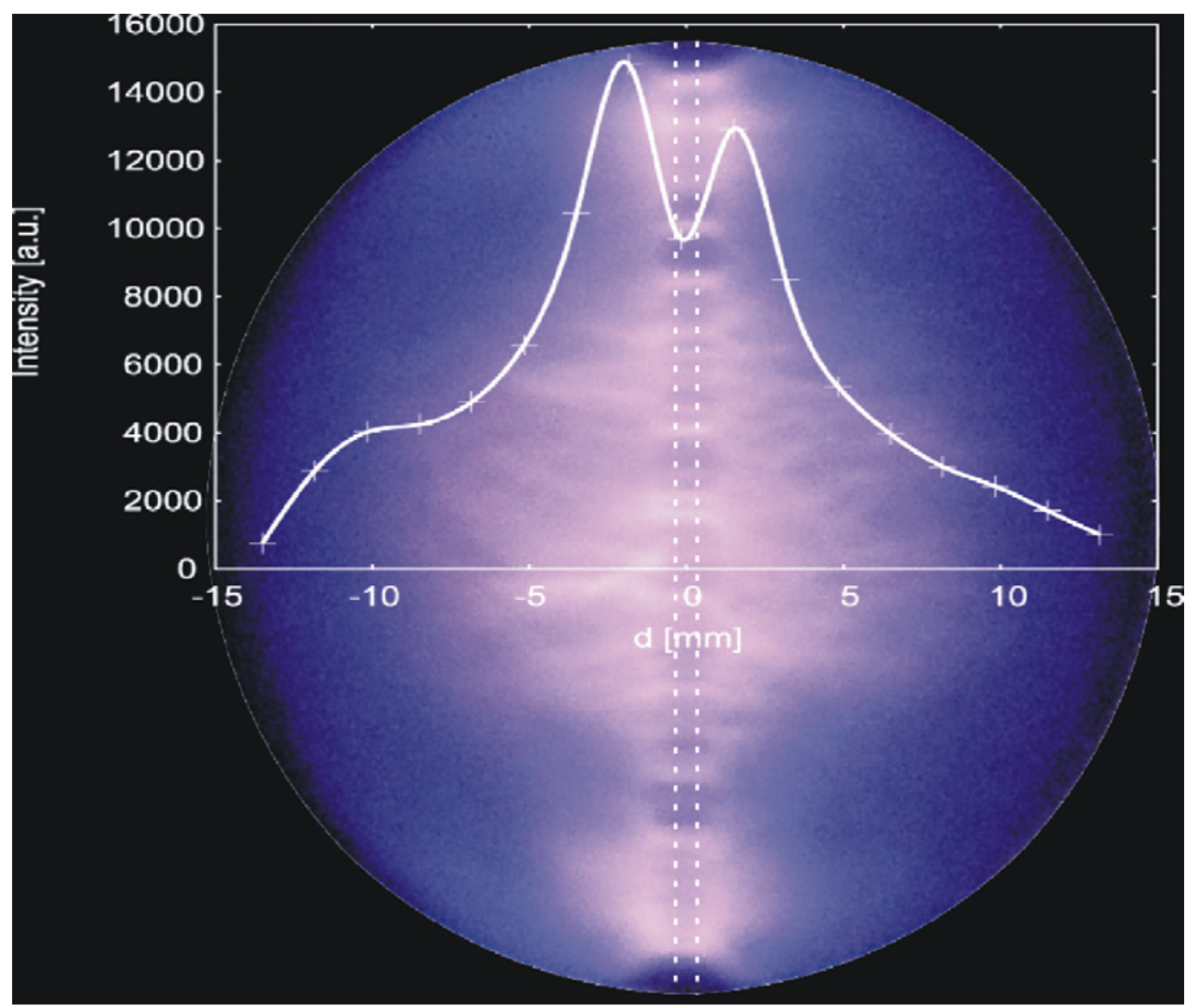

FIGURE 4. CCD camera photo of the DCSBD in ambient air taken using wide electrodes with a weak curvature at the minimal inter-electrode gap of $0.7 \mathrm{~mm}$ (indicated by dash lines) and the $30 \%$ overvoltage.

Such a study is exemplified by Fig. 4, where wide and long electrodes with a weak curvature were used to eliminate edge effects and study spatial distribution of the plasma layer. It is evident that at the higher gap overvoltage used the radiation from the diffuse plasma regions above the electrodes is much stronger than from the filamentary plasma above the electrode gap, and the diffuse plasma propagates to the distance of several $\mathrm{mm}$ from the electrode edge. The ability of DCSBD to generate 
such a "useful" diffuse plasma, which was not known earlier, is the primary feature that distinguishes DCSBDs from prior atmospheric-pressure coplanar barrier discharges studied in oxygen and ambient air $[21,22]$.

To obtain a more detailed insight into the discharge formation mechanism our current efforts are focusing also on studying the dynamics of the elementary DCSBD discharge using a high speed camera [23] and the technique of spatially resolved cross-correlation spectroscopy [24].

\section{APPLICATIONS OF AMBIENT AIR DCSBD}

DCSBD was originally designed to fulfill the specific requirements of the textile nonwoven industry for hydrophilization of lightweight (i.e. with the thickness on the order of $0.1 \mathrm{~mm}$ only) polypropylene (PP) nonwoven (NW) fabrics, which are widely used in personal care absorbent products, such as feminine hygiene products, diapers, adult incontinent products, and medical products as gowns and surgical drapes [27]. Since cost efficiency and manufacturing speed (up to $1000 \mathrm{~m} / \mathrm{min}$ ) are the driving forces for process development in nonwovens industry, the expected economic and operation advantages lead us to consider the construction of an ambient air plasma source generating a thin layer of high-power density $\left(\sim 100 \mathrm{~W} / \mathrm{cm}^{3}\right)$ air plasma of the same thickness $(\sim 0.1 \mathrm{~mm})$ as the treated nonwoven fabrics. Since less than $30 \mu \mathrm{m}$ thick fibers of PP NW fabrics are a very thermal sensitive material, critical was to keep the air plasma gas temperature less than some $100-150^{\circ} \mathrm{C}$.

After a decade of development, the DCSBD plasma source is proven to be truly promising technology for this specific application: It was successfully tested for the in-line activation (i.e. non-permanent hydrophilization) of PP NW at the line speeds up to $300 \mathrm{~m} / \mathrm{min}$. with an extremely low energy consumption less than $0.3 \mathrm{kWh} / \mathrm{kg}[20,27]$. The DCSBD plasma activated PP NWs have been successfully tested e.g. for post-plasma grafting of polyacrylic acid $[25,26]$, chitosan immobilization [27], immobilization of nanopowders [28], improvement of flexoprint quality, and electroless metal plating.

Surprisingly it was found that the ambient air DCSBD plasma source is capable to hydrophilize lightweight $\left(10-20 \mathrm{~g} / \mathrm{m}^{2}\right)$ PP NWs also permanently with low power consumption of some $1 \mathrm{kWh} / \mathrm{kg}$, and without any pinholing or critical changes in tensile strength of the fabric. As for the observed treatment permanency, differentiating the DCSBD source from standard volume DBD („,corona“) treaters, we suppose that it can be explained as follows: The hydrophobic recovery of PP surfaces after treatment with volume DBD discharges burning in atmospheric-pressure ambient air is mainly due to surface reorientation of the polar groups caused by the air plasma treatment from the surface into the bulk and reorientation of nonpolar groups from the bulk to the surface, respectively. If, however, crosslinking is induced at the PP surface, the crosslinking tends to limit PP chain mobility, thus significantly slowing the "hydrophobic recovery" process and therefore stabilising surface wettability over time $[13,14]$. It is known that, using atmospheric-pressure helium working gas in the volume DBD electrode geometry, the polypropylene wettability increase by a diffuse glow volume DBD is greater and more stable than by a filamentary DBD $[13,14]$. Based on this we hypothesize that the more diffuse and highly nonequilibrium DCSBD air plasma is more efficient in generating such crosslinking-stabilized wettable PP surfaces than the filamentary plasma generated by conventional volume DBDs. An additional experimental evidence that can be cited in support of this hypothesis are our electron spin resonance results indicating a crosslinking induced by plasma treatment on PP NW fibres surfaces permanently hydrophilized using a similar plasma source [31].

Besides the PP NWs treatment, the potential of DCSBD plasma sources for textile surface activation has already been demonstrated in many contexts, such as e.g. in an improvement of polyester cords to rubber [29], and a narrow-web DCSBD plasma treater shown in Fig. 5 is commercially available for a wide variety of textile materials for the treatment speeds up to $100 \mathrm{~m} / \mathrm{min}$. 


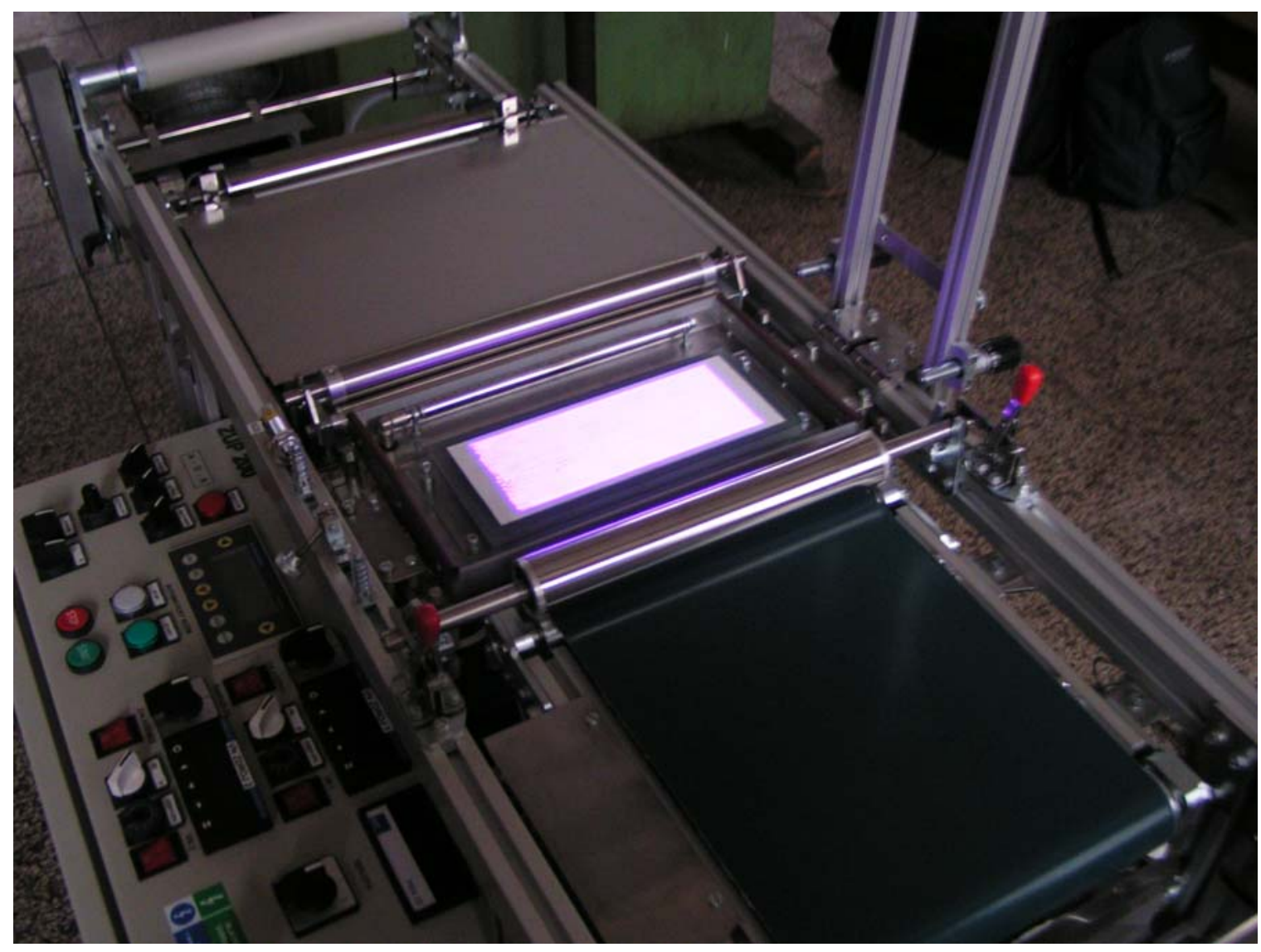

FIGURE 5. A commercial narrow (up to $21 \mathrm{~cm}$ ) web DCSBD plasma surface treater.

Another potential area for significant applications of ambient air DCSBD is treatment of low-addedvalue cellulose-based materials as paper and wood. Because of their surface porosity, from the viewpoint of the discharge physics these materials are very close to the fabric. As for the wood surface treatment, the DCSBD appears to outperform the know volume DBDs used for this applications [15] in less energy consumption and in eliminating the safety hazard associated with the use of treated wood workpiece as the discharge counter-electrode, as well as with the operation in dusty and humid industrial environment. A more detailed discussion of these applications may be found in references [11, 30, 31].

Based on encouraging preliminary results $[32,33]$ we foresee the potential applications of the air DCSBD plasma source in flat glass surface cleaning, where DCSBD offers significant advantages over other atmospheric-pressure plasma sources tested for this application [32, 33]. For example, it was found [32] that the DCSBD energy consumption for the glass surface cleaning (hydrophilization) is approximately $5 \times 10^{3} \mathrm{~W} \cdot \mathrm{sec} / \mathrm{m}^{2}$ that is of 1 to 2 orders less than in the case of the plasma jet cleaning with the corresponding reduction in nitrogen oxides and ozone generation.

\section{CONCLUSIONS}

The results presented indicate that the novel ambient air DCSBD plasma sources based on DCSBD have a significant commercial potential for high-speed on-line plasma surface activation and cleaning of low-added value materials as fabrics, paper, wood, and glass. Of particular importance are considerable operational cost advantages comparing to any other plasma source hitherto tested for such applications. Other factors favoring DCSBD plasma sources are the safety, scalability to large area treatments, robustness, and operability in dusty and humid industrial environment. 


\section{ACKNOWLEDGEMENTS}

At the Comenius University, Bratislava this work was supported by the Slovak Research and Development Agency under the contracts APVV-20-033004 and APVV-0485-06; by the Slovak Grant Agency VEGA under the contract No. 1/4014/07, and by the Ministry of Education of the Slovak republic under the contract No. 4/2036/08. At the Masaryk University, Brno it was supported by the Czech Program "Nanotechnology for the Society" under the contract KAN101630651.

\section{REFERENCES}

[1] J.R. Roth, Industrial Plasma Engineering, Vol. II - Applications to Non-Thermal Plasma Processing (Institute of Physics Publishing 2001, Bristol and Philadelphia)

[2] R. Shishoo, Woodhead Pul. In Textiles (2007)

[3] A.P. Napartovich, Plasmas and Polymer 6 (2001), 1-14

[4] U. Kogelschatz, IEEE Transactions on Plasma Sci, 30 (2002), 1400-1408

[5] H. Hermann et al, Glass Processing Days 2005, Tampere, Finland, 2005, 1-3

[6] Rombolà, F. Parisi, C. Pavan, D. Dapra, Czech. J. Phys. 56 (2006), 1021-1028

[7] D. Trunec, A. Brablec, J. Buchta, J. Phys. D: Appl. Phys. 34 (2001), 1697-1699

[8] F. Massines, G. Gouda, J. Phys. D: Appl. Phys. 31 (1998), 3411-3420

[9] R. Brandenburg, V. A. Maiorov, Yu B. Golubovskii, H-E. Wagner1, J. Behnke, J. F. Behnke, J. Phys. D: Appl. Phys. 38 (2005) 2187-2197

[10] G Borcia, C.A. Anderson and N.M.D Brown, Plasma Sources Sci. Technol. 12 (2003)

[11] L. Černáková, P. St’ahel, D. Kováčik, K. Johansson, M., Černák, in Proceedings of the 9th Tappi Advanced Coating Fundamentals Symposium, Turku 2006, Finland, 7-17

[12] G. Borcia, N.M.D. Brown, D. Dixon , R. McIlhagger, Surface and Coatings Technology, 179 (2004)

[13] F Massines and G Gouda, J. Phys. D: Appl. Phys. 31 (1998), 3411-3420

[14] F. Massines, G. Gouda, N. Gherardi, M. Duran, E. Croquesel, Plasmas and Polymers, 6, 1/2 (2001), 35-49

[15] P. Rehn, W. Viol, Holz als Roh- und Werkstoff 61, (2003)

[16] E. Temmerman, Y. Akishev, N. Trushkin, Ch. Leys, J. Verschuren, J. Phys. D: Appl. Phys., 38 (2005), 505509

[17] J.R. Roth, J. Rahel, X. Dai and D.M. Sherman, J. Phys. D: Appl. Phys. 38 (2005), 555-567

[18] I.Y. Murokh., Tri-Star Technologies, 2005

[19] M. J. Shenton, G. C. Stevens, N. P. Wright, X. Duan, J. Polym. Sci. Part A, Polym. Chem. 40 (2002), 95109

[20] M. Šimor, J. Rahel, P. Vojtek, A. Brablec, M. Černák, Appl. Phys. Lett. 81 (2002), 2716-2718

[21] V.I. Gibalov, G.J. Pietsch, J. Phys. D: Appl. Phys., 37 (2004), 2093-2100

[22] L. Hulka, G.J. Pietsch, HAKONE VIII, Puhajarve, Estonia, 2002, 259-363

[23] T. Hoder, D. Chorvát, J. Ráhel', M. Černák, In Proceedings of 3rd International Workshop on Microplasmas, Greifswal, 2006, (Institut für Niedertemperatur-Plasmaphysik e.V.) ISBN 3-00-018723-5

[24] T. Hoder, M Š́ra, K.V.Kozlov, and H-E Wagner, J. Phys. D: Appl. Phys. 41 (2008) (in print)

[25] M. Šimor, J. Ráhel, D. Kováčik, A. Záhoranová, M. Mazur, M. Černák, 12th TANDEC International Nonwovens Conference, Knoxville, 2002, (UT Conference Center, Knoxville, Tennessee, USA), 1-15

[26] L'. Černáková et al., Plasma Chemistry and Plasma Processing, 25, 4 (2005)

[27] M. Černák, M. Čewrnáková, M. Mikula, D. Kováčik, P. St’ahel, A. Buček, 15th Symposium on Applications of Plasma Processes, Bratislava, 2005, 77-78

[28] L. Černáková, R. Szabová, M. Wolfová, A. Buček, and M. Černák, Fibres \& Textiles in Eastern Europe, 15 (2007)

[29] I. Hudec, M. Jaššo, H. Krump, M. Černák and V. Šuriová, e-Journal of Soft Materials, 2 (2006)

[30] A. Toth, L'. Černáková, M. Černák, K. Kunovská, Holzforschung 61, (2007)

[31] M. Odrášková, J. Ráhel, A. Zahoranová, R.Tiňo, and M. Černák, Plasma Chemistry and Plasma Processing 28 (2008)

[32] M. Černák, A. Buček, T. Homola, M. Aranyošiová, D. Velič, J. Havel, and M. Černák, 16th International Colloquium on Plasma Processes, Paris, 2007, p.3

[33] http://gimmel.ip.fmph.uniba.sk/glass/ 